\title{
Proteomic analysis in canine leishmaniasis
}

\author{
D. Britti • M. Gaspari • G. Massimini • F. Casalinuovo • \\ V. M. Morittu • G. Cuda
}

Published online: 5 May 2010

(C) Springer Science+Business Media B.V. 2010

\begin{abstract}
The aim of this study was to perform a proteomic analysis on serum of dogs naturally infected with Leishmania parasite. Sera from 24 dogs, n. 8 with high IFAT titre of anti-Leishmania antibodies $(\geq 1: 640), \mathrm{n} .8$ with uncertain titre $(=1: 40)$, and n. 8 with IFAT negative were used. Sera of each group were pooled together to form three pools: P (high titre); $\mathrm{U}$ (uncertain titre); and $\mathrm{N}$ (negative). The $\mathrm{P}$ pool was analyzed, using a mass spectrometry-based approach to search for Leishmania proteins (qualitative analysis). In a second experiment, protein signal intensities of $\mathrm{U}$ and $\mathrm{P}$ pools were compared with the signal intensities of $\mathrm{N}$ pool by a quantitative mass spectrometry method based on isotopic dilution. The quantitative analysis detected a total of 70 proteins, of which 17 and 5 resulted over- and under-represented in sample $\mathrm{P}$, respectively.
\end{abstract}

Keywords Dog $\cdot$ Proteomics $\cdot$ Leishmaniasis $\cdot$ Diagnosis $\cdot$ Serum proteins

$\begin{array}{ll}\text { Abbreviations } \\ \text { CanL } & \text { canine leishmaniasis } \\ \text { MS/MS } & \text { tandem mass spectrometry } \\ \text { nanoLC } & \text { nano liquid chromatography } \\ \text { iTRAQ } & \text { isobaric tags for relative and absolute quantitation } \\ \text { IFAT } & \text { immunofluorescent antibody test } \\ \text { PCR } & \text { polymerase chain reaction }\end{array}$

D. Britti $(\bowtie) \cdot$ M. Gaspari $・$ V. M. Morittu $\cdot$ G. Cuda Dipartimento Medicina Sperimentale e Clinica Università degli Studi di Catanzaro "Magna Græcia", viale Europa, Campus S. Venuta, 88100 Catanzaro, Italy e-mail: britti@unicz.it

G. Massimini

Medico Veterinario Libero Professionista, Ortona, CH, Italy

F. Casalinuovo

Istituto Zooprofilattico Sperimentale del Mezzogiorno, Sez. di Catanzaro, Catanzaro, Italy 


\section{Introduction}

CanL is a protozoal infection with zoonotic and public health aspects that cause a profound modulation of the host's immune response resulting in successful infection with Leishmania. Studies have been performed in CanL to investigate the humoral and cellular immune responses (Barbiéri 2006), the serum protein electrophoretic pattern and its modifications (Bizzeti 1998). Nevertheless, little has been directed in the recent years to detect and quantify the serum proteins in dogs naturally infected with Leishmania for evaluating their potential usefulness and clinical relevance (Martínez-Subiela et al. 2003). Currently, in human diagnostic pathology the identification of serum proteins by proteomic analysis is an useful tool for several diseases (Issaq et al. 2007). This analytical procedure consists of a tryptic digestion of a protein mixture, the subsequent separation of produced peptides (i.e., by use of a nanoLC), and the peptide identification by use of a MS/MS analysis. The number of detectable proteins increases with the time of the chromatographic separation. The peptide separation may be alternatively performed by use of a twodimensional chromatography combining two separation techniques based on the independent physicochemical properties of the analytes (i.e., ionic exchange and reverse phase). The high concentrations of albumin and immunoglobulins in the serum may interfere with the MS/MS analysis because the derived peptides will be preferentially selected by the spectrometer. To reduce the interference, it is required a high resolution chromatographic separation before the MS/MS analysis of peptide mixtures. By the procedure of enzymatic digestion and MS/MS analysis, a qualitative analysis of the protein content of a sample is achieved. To evaluate quantitative differences of a single protein in different samples, an isotopic labelling of peptides by iTRAQ may be performed (DeSouza et al. 2005). In this technique, each sample is labelled with a different tag iTRAQ before the MS/MS analysis. Each tag corresponds to a characteristic fragment in the MS/MS analysis, thus it is possible to identify any single tag on the MS/MS spectrum. Quantitative relative values of different proteins of a sample may be obtained by comparing intensity areas of tag signals produced from the unknown sample and the reference sample. The aim of the study reported here was to perform, for the first time, a proteomic analysis on the serum of dogs naturally infected with Leishmania in an attempt to detect the proteins potentially expressed by the parasite (qualitative analysis). Furthermore, quantitative differences (over- or under-expression) of proteins in serum from infected and non-infected dogs were also evaluated (quantitative analysis).

\section{Materials and methods}

Serum samples were collected from dogs housed in a public kennel. Dogs were divided in three groups on the basis of IFAT titre results: IFAT titre $\geq 1: 640(\mathrm{n}=8)$, high titre; IFAT titre $=1: 40(n=8)$, uncertain titre; and IFAT negative $(n=8)$ (Table 1). Physical examinations and serological assays were performed to rule out concurrent diseases. Prior to perform the proteomic analysis, equal amounts of sera from each group were pooled to obtain three samples named as follows: $\mathrm{P}=$ high titre; $\mathrm{U}=$ uncertain titre; $\mathrm{N}=\mathrm{IFAT}$ negative. Qualitative analysis: $10 \mu \mathrm{L}$ aliquot was taken from the P pool. Proteins were precipitated, resuspended, denatured, and digested by trypsin. Resulting peptides were resolved by isoelectric point in 24 fractions by using a Off-gel electrophoresis instrument (Agilent Technologies, Santa Clara, CA). Off-gel fractions were analyzed in duplicate by nanoLC coupled to MS/MS (nanoLC-MS/MS). Spectra were obtained and used to interrogate MSDB database using the 
Table 1 G. sh. = German shepherd; Mo = Mongrel; Med = Medium; Neg. = negative

\begin{tabular}{|c|c|c|c|c|}
\hline & Breed & Size & & IFAT \\
\hline \multirow[t]{8}{*}{ High IFAT titre } & Mo. & Med. & $\mathrm{F}$ & $1: 1280$ \\
\hline & Mo. & Med. & M & $1: 1280$ \\
\hline & G. sh. & Large & $\mathrm{F}$ & $1: 1280$ \\
\hline & Mo. & Med. & $\mathrm{F}$ & $1: 1280$ \\
\hline & Mo. & Med. & $\mathrm{F}$ & $1: 1280$ \\
\hline & Mo. & Large & M & $1: 640$ \\
\hline & Mo. & Med. & M & $1: 640$ \\
\hline & Mo. & Med. & $\mathrm{F}$ & $1: 640$ \\
\hline \multirow[t]{8}{*}{ Uncertain IFAT titre } & Mo. & Med. & $\mathrm{F}$ & $1: 40$ \\
\hline & Mo. & Med. & $\mathrm{F}$ & $1: 40$ \\
\hline & Mo. & Med. & $\mathrm{F}$ & $1: 40$ \\
\hline & Mo. & Med. & $\mathrm{F}$ & $1: 40$ \\
\hline & Mo. & Med. & $\mathrm{M}$ & $1: 40$ \\
\hline & Mo. & Med. & $\mathrm{F}$ & $1: 40$ \\
\hline & Mo. & Med. & M & $1: 40$ \\
\hline & Mo. & Med. & $\mathrm{F}$ & $1: 40$ \\
\hline \multirow[t]{8}{*}{ IFAT negative } & Mo. & Med. & $\mathrm{F}$ & Neg. \\
\hline & Mo. & Med. & $\mathrm{F}$ & Neg. \\
\hline & Mo. & Med. & M & Neg. \\
\hline & Mo. & Med. & M & Neg. \\
\hline & Mo. & Med. & $\mathrm{F}$ & Neg. \\
\hline & Mo. & Med. & $\mathrm{M}$ & Neg. \\
\hline & Mo. & Med. & $\mathrm{F}$ & Neg. \\
\hline & Mo. & Med. & $\mathrm{F}$ & Neg. \\
\hline
\end{tabular}

Mascot search engine (www.matrixscience.com). Quantitative analysis: $10 \mu \mathrm{L}$ aliquots were taken from each of the three sample pools (P, U and N). Each aliquot was diluted in 9 volumes of water. Serum proteins were then precipitated by adding trichloroacetic acid to a final concentration of $10 \%(\mathrm{w} / \mathrm{v})$ and incubated at $4{ }^{\circ} \mathrm{C}$ overnight. Protein pellets were resuspended in $300 \mu \mathrm{L}$ of iTRAQ buffer. The total protein concentration was determined by the bicinchoninic acid assay (Pierce, Rockford, IL), according to the manufacturer's specifications. Protein concentrations were as follows: $\mathrm{N}$ pool $=4.95 \mathrm{mg} / \mathrm{mL}, \mathrm{U}$ pool $=4.37 \mathrm{mg} / \mathrm{mL}, \mathrm{P}$ pool $=4.60 \mathrm{mg} / \mathrm{mL}$. On the basis of these values, aliquots of each sample containing $100 \mu \mathrm{g}$ of total proteins were taken. Protein concentration was brought to $3.33 \mathrm{mg} / \mathrm{mL}$ for all samples by diluting in iTRAQ buffer. Protein reduction/alkylation, tryptic digestion, and iTRAQ labelling were performed according to the manufacturer's protocol (Applied Biosystems, Foster City, CA). The N, U, and P pools were labelled with isobaric tag 114,116 , and 117 , respectively. The three pools were mixed and their volume reduced to a few microliters by vacuum centrifugation. Peptides were then purified by solid-phase extraction and fractionated by strong cation exchange chromatography and the 20 fractions obtained were analyzed by use of a nanoLC-MS/MS method with an Ultimate nanoLC system (Dionex, Sunnyvale, CA) coupled to a QSTAR XL hybrid LC-MS/MS (Applied Biosystems, Foster City, CA). The MS/MS spectra were searched on the Mascot search engine against the Swiss-prot database (taxonomy: other mammalia). Signal 
intensities for the iTRAQ reporter ions 116 and 117 (U and P pool, respectively) were calculated and compared with the signal intensities obtained for the reporter ion 114 ( $\mathrm{N}$ pool). The $\mathrm{P} / \mathrm{N}$ ratios for each protein were normalized, using the median value of the complete set of $\mathrm{P} / \mathrm{N}$ ratios (obtained from over 400 peptides) as a normalization factor. The same normalization procedure was adopted for $\mathrm{U} / \mathrm{N}$ ratios. After normalization, iTRAQ ratios below 0.7 or above1.5 were considered significant.

\section{Results}

About 10,000 MS/MS spectra were generated by 48 nanoLC-MS/MS runs of the $\mathrm{P}$ pool. After database research, more than 500 peptide sequences were identified and assigned to 105 proteins. Nevertheless, neither of these proteins could be univocally attributable to the Leishmania parasite. Of the 105 proteins, 70 were identified and quantified by proteomic analysis (Table 2). The concentration of 22 proteins of the $\mathrm{P}$ pool was changed when

Table 2 Quantitative relative values for serum proteins from dogs with high (P) and uncertain (U) IFAT titers for CanL calculated by comparing intensity areas of tag signals produced from the $\mathrm{P}$ and $\mathrm{U}$ samples with the reference IFAT negative $(\mathrm{N})$ sample and expressed as ratios. For all analyses, $\mathrm{P} / \mathrm{N}$ (and $\mathrm{U} / \mathrm{N}$ ) ratios $<0.7$ and $>1.5$ represent a significant variation and the under- and over-expression of the protein, respectively; ratios $=1$ represent the absence of variation. Standard deviations $(S D)$ of the ratios are reported for the proteins that were identified from more than a tryptic peptide. Only the proteins with a significant variation are listed the complete list is available upon request from the Authors

\begin{tabular}{|c|c|c|c|c|c|c|c|}
\hline $\mathrm{N}$ & Cod. Swiss Prot & Protein description & Peptides & $\mathrm{U} / \mathrm{N}$ & $S D$ & $\mathrm{P} / \mathrm{N}$ & $S D$ \\
\hline 1 & SAA CANFA & Serum Amyloid A & 1 & 1.7 & - & 4.3 & - \\
\hline 2 & APOE_CANFA & Apolipoprotein E & 12 & 1.1 & 0.3 & 3.8 & 0.7 \\
\hline 3 & APOC2_CANFA & Apolipoprotein C-II & 2 & 1.0 & 0.2 & 3.2 & 0.2 \\
\hline 4 & AT11B_RABIT & Probable phospholipid-transporting ATPase & 1 & 1.2 & - & 3.2 & - \\
\hline 5 & HV02_CANFA & Ig heavy chain $\mathrm{V}$ & 3 & 1.6 & 0.2 & 3.1 & 0.2 \\
\hline 6 & ITIH4_PIG & Inter- $\alpha$-trypsin inhibitor heavy chain $\mathrm{H} 4$ & 1 & 1.4 & - & 2.6 & - \\
\hline 7 & IL2RG_CANFA & IL-2 receptor $\gamma$-chain & 1 & 2.1 & - & 2.6 & - \\
\hline 8 & TRPV1_CANFA & $\begin{array}{l}\text { Transient receptor potential cation } \\
\text { channel subfamily } \mathrm{V}\end{array}$ & 1 & 1.4 & - & 2.3 & - \\
\hline 9 & HPT_CANFA & Haptoglobin & 54 & 1.5 & 0.7 & 2.2 & 0.9 \\
\hline 10 & DIMT1_BOVIN & Probable dimethyladenosine transferase & 1 & 1.1 & - & 2.2 & - \\
\hline 11 & APOA4_PIG & Apolipoprotein A-IV & 3 & 1.1 & 0.1 & 2.1 & 0.1 \\
\hline 12 & KV1_CANFA & Ig-kappa chain & 2 & 1.2 & 0.0 & 1.8 & 0.1 \\
\hline 13 & FIBA_CANFA & Fibrinogen alpha chain & 10 & 1.2 & 0.2 & 1.7 & 0.1 \\
\hline 14 & FIBB_CANFA & Fibrinogen beta chain & 4 & 1.1 & 0.3 & 1.7 & 0.3 \\
\hline 15 & APOC1_CANFA & Apolipoprotein C-I & 8 & 1.0 & 0.2 & 1.7 & 0.1 \\
\hline 16 & NDKA_CANFA & Nucleoside diphosphate kinase A & 1 & 1.2 & - & 1.7 & - \\
\hline 17 & A2MG_BOVIN & Alpha-2-macroglobulin & 1 & 1.0 & - & 1.6 & - \\
\hline 66 & CO8B_RABIT & Complement C8 & 1 & 0.9 & - & 0.6 & - \\
\hline 67 & TFR1_CANFA & Transferrin receptor protein 1 & 1 & 0.8 & - & 0.6 & - \\
\hline 68 & PRKDC_CANFA & DNA-dependent protein kinase catalytic subunit & 1 & 0.6 & - & 0.6 & - \\
\hline 79 & ANGT_SHEEP & Angiotensinogen & 1 & 0.8 & - & 0.5 & - \\
\hline 70 & PON1_RABIT & Serum paraoxonase/arylesterase 1 & 1 & 0.6 & - & 0.4 & - \\
\hline
\end{tabular}


compared with the control (N pool). Particularly, 17/22 (77,3\%) proteins were overexpressed and 5/22 proteins $(22,7 \%)$ were under-expressed.

\section{Discussion}

To the authors' knowledge, the results reported here represent the first of a proteomic analysis in dogs naturally infected with Leishmania parasites. Results of the present study indicate that the sensibility of a classic proteomic analysis by twodimensional separation and MS/MS is not adequate to detect protein fragments of Leishmania spp. on serum of naturally infected dogs. Consequently, the currently nanoLC-MS/MS technique seems to not have a proper usefulness for diagnosis of CanL, compared with other assays, such as the IFAT for detecting anti-Leishmania antibodies or the PCR for amplifying nucleic acids fragments of the parasite. Concerning the quantitative comparison of the over- or under-expressed proteins in infected vs non-infected dogs, our results might open attractive fields of research aimed to clarify the pathogenesis of CanL and human leishmaniasis and to improve the diagnostic and prognostic approach to the disease. Thus, it might be interesting to evaluate if the over- and under-expressed proteins (Table 2) represent a specific protein pattern for $\mathrm{CanL}$ or they are common to other pathologic processes (i.e., inflammatory, infective, and neoplastic conditions) in dogs. Additionally, specific protein patterns might be related to specific classes of symptoms (i.e., asymptomatic, oligosymptomatic, and symptomatic) or to severity of the disease (i.e., acute $v s$ chronic; symptomatic $v s$ asymptomatic azotemia). In our study, the over-expressed proteins serum amyloid A (SAA) and haptoglobin, which are referred to as acutephase proteins, were detected both in positive and uncertain sera. This is consistent with results of previous studies both in CanL (Martínez-Subiela et al. 2003) and in human visceral leishmaniasis (Wasunna et al. 1995), revealing a high sensitivity of the acute-phase proteins to detect infected dogs or humans with and without clinical signs of disease. Further, in patients with visceral leishmaniasis the increased serum levels of SAA and other acute-phase proteins (C-reactive protein and $\alpha_{1}$-acid glycoprotein) progressively decreased with effective therapy while remained significantly high in those patients slower to clear parasites (Wasunna et al. 1995). Dogs with CanL had also increased serum levels of SAA, haptoglobin, C-reactive protein, and ceruloplasmin at the time of diagnosis. Nevertheless, the levels of C-reactive protein and ceruloplasmin only decreased significantly after therapy, suggesting their potential use for monitoring the initial response of dogs to treatment (Martínez-Subiela et al. 2003). Finally, among the over-expressed proteins we detected IL-2 receptor $\gamma$-chain, which is a basic sub-unit of IL-2 receptor. Although the gene $\gamma$-chain mutations have been related to immunodeficiency and dysfunctions of T, NK, and B cells in humans (Sugamura et al. 1996), the relevance of this protein in the susceptibility of leishmaniasis remains to be evaluated. Overall, results of our study suggest that the quantitative analysis by the use of an isotopic labelling, the two dimensional chromatographic separation, and the MS/MS analysis permits a wide screening of the serum proteins in infected compared with non-infected dogs. Proteomic analysis is faster and less expensive than ELISA and PCR techniques with regard to the number of serum proteins that may be simultaneously investigated, thus it is an attractive procedure that open possibilities for the proper comprehension of pathologies also in veterinary medicine. 


\section{References}

Barbiéri C.L., 2006. Immunology of canine leishmaniasis. Parasite Immunology, 28, 329-337.

Bizzeti M., 1998. La sieroelettroforesi per il controllo della leishmaniosi nel cane. Obiettivi e Documenti Veterinari, 19, 11-15.

DeSouza L., Diehl G., Rodrigues M.J., Guo J., Romaschin A.D., Colgan T.J., Siu K.W., 2005. Search for cancer markers from endometrial tissues using differentially labeled tags ITRAQ and cICAT with multidimensional liquid chromatography and tandem mass spectrometry. Journal of Proteome Research, 4, 377-386.

Issaq H.J., Xiao Z., Veenstra T.D., 2007. Serum and Plasma proteomics. Chemical Reviews, 107, 3601-3620.

Martínez-Subiela S., Bernal L.J., Cerón J.J., 2003. Serum concentrations of acute-phase proteins in dogs with leishmaniosis during short-term treatment. American Journal of Veterinary Research, 64, 1021-1026.

Sugamura K., Asao H., Kondo M., Tanaka N., Ishii N., Ohbo K., Nakamura M., Takeshita T., 1996. The interleukin-2 receptor gamma chain: its role in the multiple cytokine receptor complexes and $\mathrm{T}$ cell development in XSCID. Annual Review of Immunology, 14, 179-205.

Wasunna K.M., Raynes J.G., Were J.B., Muigai R., Sherwood J., Gachihi G., Carpenter L., McAdam K.P., 1995. Acute phase protein concentrations predict parasite clearance rate during therapy for visceral leishmaniasis. Transaction of the Royal Society of Tropical Medicine and Hygiene, 89, 678-681. 